\title{
Diazocine-functionalized TATA platforms
}

\author{
Roland Löw ${ }^{1}$, Talina Rusch ${ }^{2}$, Fynn Röhricht ${ }^{1}$, Olaf Magnussen ${ }^{2}$ and Rainer Herges ${ }^{* 1}$
}

\author{
Full Research Paper \\ Address: \\ ${ }^{1}$ Otto Diels Institute of Organic Chemistry, University of Kiel, \\ Otto-Hahn-Platz 4, 24118 Kiel, Germany and ${ }^{2}$ Institute for \\ Experimental and Applied Physics, University of Kiel, Leibnizstraße \\ 19, 24098 Kiel, Germany \\ Email: \\ Rainer Herges ${ }^{*}$ - rherges@oc.uni-kiel.de \\ * Corresponding author

\section{Keywords:} \\ cis-trans isomerization; diazocine; molecular switch; photochrome; \\ self-assembled monolayers; TATA platform
}

\author{
Beilstein J. Org. Chem. 2019, 15, 1485-1490. \\ doi:10.3762/bjoc. 15.150 \\ Received: 17 April 2019 \\ Accepted: 28 June 2019 \\ Published: 05 July 2019 \\ This article is part of the thematic issue "Molecular switches". \\ Guest Editor: W. Szymanski \\ (C) 2019 Löw et al.; licensee Beilstein-Institut. \\ License and terms: see end of document.
}

\begin{abstract}
Recently, it has been shown that the thermochemical cis $\rightarrow$ trans isomerization of azobenzenes is accelerated by a factor of more than 1000 by electronic coupling to a gold surface via a conjugated system with 11 bonds and a distance of $14 \AA$. The corresponding molecular architecture consists of a platform (triazatriangulenium (TATA)) which adsorbs on the gold surface, with an acetylene spacer standing upright, like a post in the middle of the platform and the azobenzene unit mounted on top. The rate acceleration is due to a very peculiar thermal singlet-triplet-singlet mechanism mediated by bulk gold. To investigate this mechanism further and to examine scope and limitation of the "spin-switch catalysis" we now prepared analogous diazocine systems. Diazocines, in contrast to azobenzenes, are stable in the cis-configuration. Upon irradiation with light of $405 \mathrm{~nm}$ the cis-configuration isomerizes to the trans-form, which slowly returns back to the stable cis-isomer. To investigate the thermal trans $\rightarrow$ cis isomerization as a function of the conjugation to the metal surface, we connected the acetylene spacer in meta (weak conjugation) and in para (strong conjugation) position. Both isomers form ordered monolayers on Au(111) surfaces.
\end{abstract}

\section{Introduction}

Catalysts increase chemical reaction rates by lowering the activation energies and thus create more favorable reaction pathways [1-4]. However, there are very few reactions which do not follow the classical Eyring theory [5,6]. The rate of these reactions is not dependent on an activation barrier but controlled by quantum mechanical transition probabilities between two quantum states [7-10]. The majority of these quantum chemically forbidden reactions are photochemical processes or transition metal reactions including transitions between spin states or electronic states. We recently discovered a purely organic system in the ground state, whose reaction rate is accelerated from days to seconds by electronic coupling to a bulk gold surface via a conjugated linker over 11 bonds and $14 \AA$ A [11]. Thermal cis $\rightarrow$ trans isomerizations of azobenzenes are usually slow with half-lives of the trans-isomer within the range of hours to days at room temperature (parent azobenzene: $4-5 \mathrm{~d}$ at $25^{\circ} \mathrm{C}$ ) [12]. Rotation around the $\mathrm{N}=\mathrm{N}$ bond is a symmetry-forbidden process and the slow isomerization proceeds via inversion at the 
$\mathrm{N}$ atoms [13]. The rate of isomerization is temperature dependent and follows a classical Arrhenius type behavior [12]. However, the rate and the mechanism change dramatically if the azobenzenes are electronically coupled to bulk gold [14-17]. To investigate the cis $\rightarrow$ trans isomerizations of azobenzenes as a function of electronic coupling systematically, we used the so-called platform approach [18]. The azobenzenes are not directly adsorbed on the surface, but covalently mounted on "TATA" (triazatriangulenium) platforms which adsorb on $\mathrm{Au}(111)$ surfaces. A spacer, such as an ethynyl group is connected to the central carbon atom like a post and the azobenzene is mounted on top of the spacer. After preparation of an ordered self-assembled monolayer on gold, the azobenzene units are freestanding upright on the surface. The platform defines the lateral distance between next neighbors and provides the free volume for unhindered isomerization of the azobenzene units $[19,20]$. The length and electronic nature of the spacer units control the distance from the surface and define the electronic coupling with the metal surface $[11,18]$. With increasing $\pi$-conjugation from the azobenzene into the platform, and thus coupling to the gold surface, the activation barrier drops to almost zero $\left(\approx 8 \mathrm{~kJ} \mathrm{~mol}^{-1}\right)$ and the frequency factors ( $\log$ A) become negative [11]. Vanishing barriers and low frequency factors are typical for non-adiabatic reactions [9]. The mechanism was elucidated as a singlet-triplet-singlet spin change process, which is forbidden in solution but mediated by coupling to the conduction band of the bulk gold. We are now exploring scope and limitations of this peculiar spin catalysis. To investigate if the reverse isomerization process from the trans to the cis-configuration would also be accelerated, and to further scrutinize the coupling effects, we prepared analogous diazocine systems. Diazocines are bridged azobenzenes [21]. Imposed by the ring strain of the central eight-membered ring, the cis-configuration (boat conformation) is more stable than the trans-isomer (twist conformation). Upon irradiation with $\approx 400 \mathrm{~nm}$ the cis-form switches to the trans-isomer, and irradiation with $\approx 500 \mathrm{~nm}$ or heating leads back to the cis-form [22]. Hence, the diazocines are quasi reversed azobenzenes that are more stable in their trans-configurations [23].

To investigate the electronic coupling effects, we synthesized two diazocine derivatized TATA platforms with ethynyl spacers (diazocine-TATAs). In compound $\mathbf{1}$ the diazocine is connected to the platform with the ethynyl group in para-position to the azo group, providing a full $\pi$-conjugation path of the $\mathrm{N}=\mathrm{N}$ unit through the ethynyl spacer into the platform. Diazocine-TATA 2 is connected in meta-position and thus interrupting conjugation [24,25]. Both diazocine-TATAs are equipped with methoxy groups, which serve as "reporter units" indicating the configuration of the molecules on metal surfaces [15]. In $\mathbf{1}$ the OMe group is attached para and in $\mathbf{2}$ the methoxy group is meta with respect to the azo group. Model calculations predict that the $\mathrm{C}_{\text {phenyl }}-\mathrm{O}$ bonds in the cis-isomers thus are parallel, and in the trans-isomers orthogonal to the surface (Figure 1). Previous investigations have shown that IRRAS (infrared absorption reflection spectroscopy) in combination with the surface selection rules (stretching mode orthogonal to the surface $\rightarrow$ high intensity, parallel to the surface $\rightarrow$ low intensity) is a suitable method to determine the configuration and to measure kinetics on surfaces [15]. The $\mathrm{C}-\mathrm{O}$ stretching frequencies proved to be ideal reporter signals to determine the configuration and to measure kinetics in monolayers of azo-TATAs on surfaces.

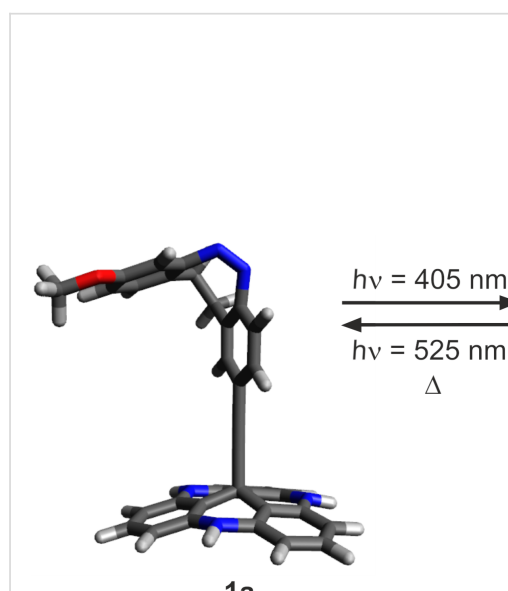

$1 \mathrm{a}$

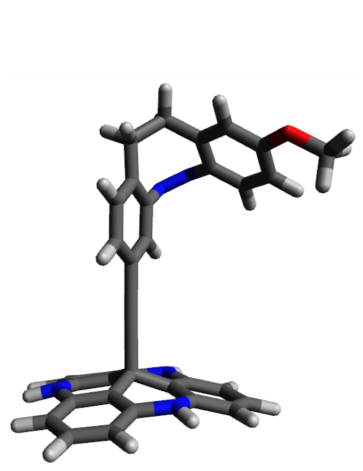

$2 a$

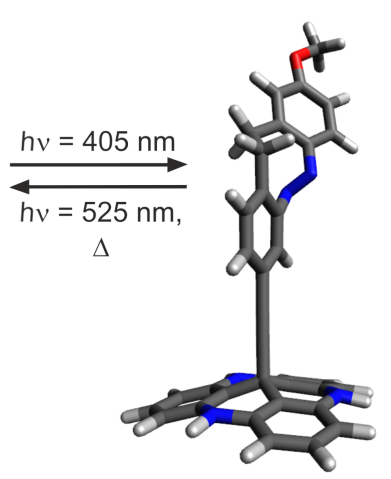

$2 \mathrm{~b}$
Figure 1: Structures of diazocine platform molecules (diazocineTATAs) $\mathbf{1}$ and $\mathbf{2}$ in cis (1a, 2a) and trans-configuration (1) $\mathbf{1}, \mathbf{2 b}$ ) (octyl side chains are replaced by protons for simplification). The cisdiazocines (1a, 2a) isomerize upon irradiation with $405 \mathrm{~nm}$ to the metastable trans-diazocines (1), 2b) and with $525 \mathrm{~nm}$ or thermally back to the cis-diazocines (1a, $2 \mathbf{a})$.

\section{Results and Discussion}

To obtain information on preferred conformations of $\mathbf{1}$ and $\mathbf{2}$ in their cis and trans-configurations and to predict thermodynamic and kinetic stabilities, we performed DFT calculations at the M06-2X/def2-TZVP level of theory (Table 1, for details see Supporting Information File 1, chapter VI). As expected for 
diazocine-based molecules our calculations predict the cis configuration for both compounds as the thermodynamically most stable isomers. For the corresponding trans-configuration two different conformations were found: the twist and the chair structures. The twist conformation is about $2.5 \mathrm{kcal} \mathrm{mol}^{-1}$ more stable than the chair conformation. Our calculations predict reaction barriers (trans-twist $\rightarrow$ cis-boat) for both compounds of approximately $23 \mathrm{kcal} \mathrm{mol}^{-1}\left(96 \mathrm{~kJ} \mathrm{~mol}^{-1}\right)$. Obviously, the TATA platform and the ethynyl spacer have only marginal effects on the isomerization process. Hence, the diazocines 1 and $\mathbf{2}$ are ideal candidates to investigate the effect of bulk gold as a function of electronic coupling (conjugation) of the azo unit to gold.

Table 1: Calculated quantum chemical energies $E_{\text {rel }}$ (M06-2X/def2TZVP) of the twist and chair conformation of the trans-configuration of para-ethynyl-substituted diazocine $\mathbf{1 b}$ (para-diazocine), and metadiazocine $\mathbf{2 b}$, relative to the boat conformation of the cis-isomers $\mathbf{1 a}$ and 2a. $\Delta H^{f}$ are the calculated reaction barriers (trans-twist $\rightarrow$ cisboat). All energies are given in $\mathrm{kcal} \mathrm{mol}^{-1}$.

\begin{tabular}{lccc} 
& $\begin{array}{c}E_{\text {rel }} \\
\text { trans twist }\end{array}$ & $\begin{array}{c}E_{\text {rel }} \\
\text { trans chair }\end{array}$ & $\Delta H^{f}$ \\
\hline para-diazocine 1 & 7.9 & 10.6 & 22.6 \\
meta-diazocine 2 & 8.0 & 10.3 & 23.0
\end{tabular}

The para-diazocine-TATA 1 was synthesized in a 5-step synthesis route (Scheme 1). Bromotoluene $\mathbf{3}$ was synthesized as described [26]. In a Sonogashira cross-coupling reaction acetylene-substituted toluene $\mathbf{5}$ was prepared from bromotoluene $\mathbf{3}$ with TMS-protected acetylene 4 (95\%). The C-C bond formation of $\mathbf{5}$ and $\mathbf{6}$ to give dibenzoyl $\mathbf{7}$ was achieved with potassium butoxide and elemental bromine (9\%) according to a literature procedure [27]. The para-ethynyldiazocine 8 was obtained by reduction of both nitro groups, followed by oxidation of the formed hydrazine (16\%). The unprotected ethynyldiazocine $\mathbf{8}$ was deprotonated with potassium hydroxide and connected to the central carbon atom of the TATA platform 9 (synthesized according to Laursen and Krebs [28]) to obtain target para-diazocine mounted on the octyl-substituted TATA platform $1(99 \%)$.

The synthesis of the meta-diazocine platform molecule 2 was achieved in a 4-step synthesis route (Scheme 2). Nitrotoluene 10 was synthesized as described in literature [29]. The reaction of ethynyltoluene $\mathbf{1 0}$ with methoxytoluene $\mathbf{1 1}$ gave dibenzoyl $12(10 \%)$ according to the same procedure as for dibenzoyl 7 (Scheme 1). Diazocine 13 was obtained by reduction and oxidation in moderate yields (22\%). The reaction of diazocine $\mathbf{1 3}$ with the TATA ion 9 gave the target diazocine 2 ( $88 \%$, Scheme 2).

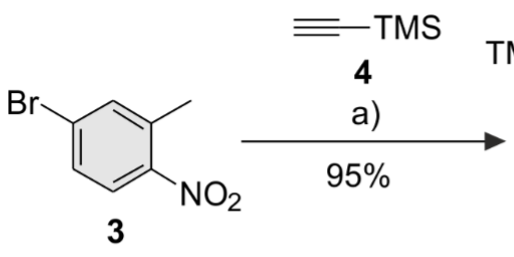<smiles>CSC#Cc1ccc([N+](=O)[O-])c(C)c1</smiles>

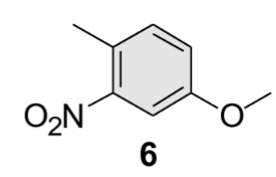

b)
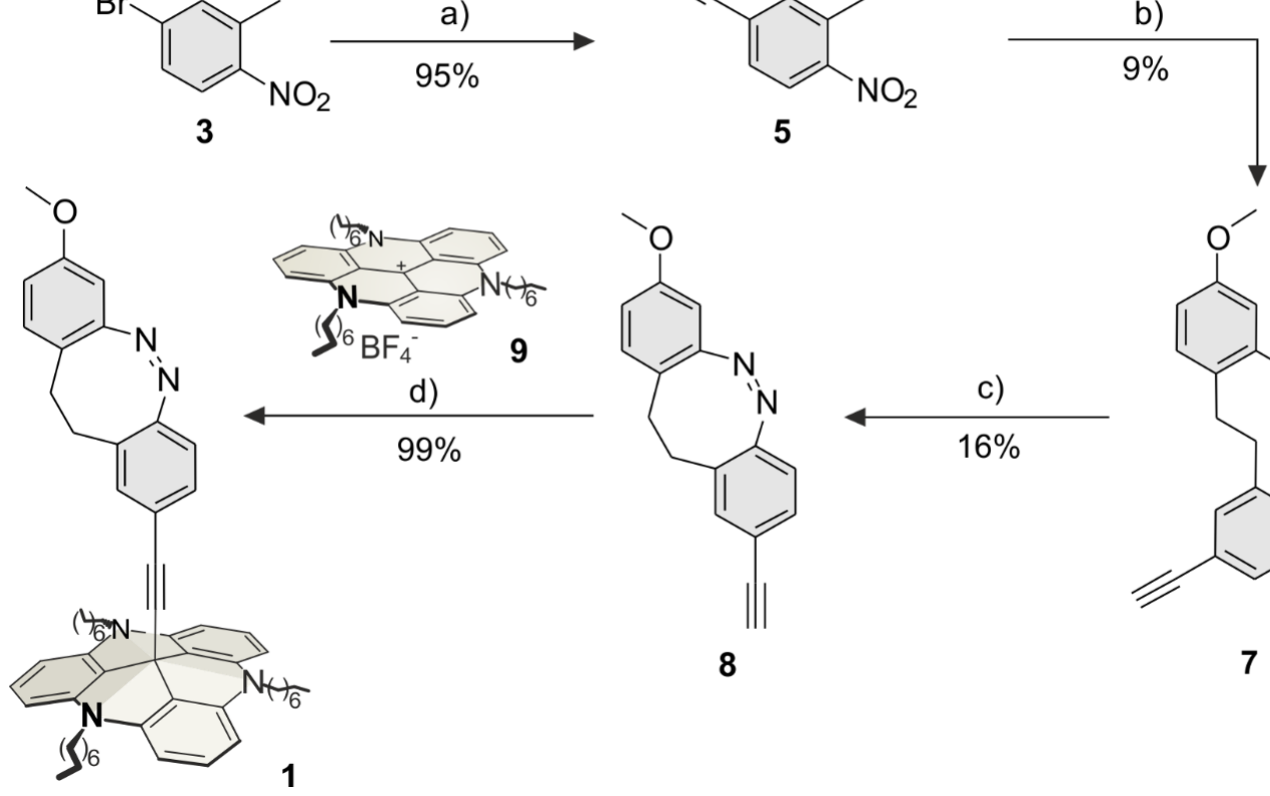

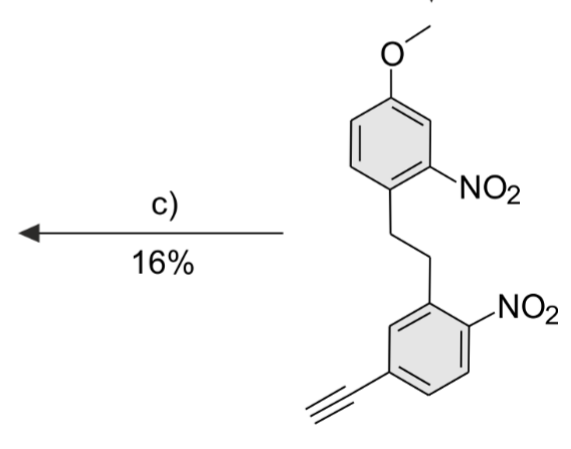

7 


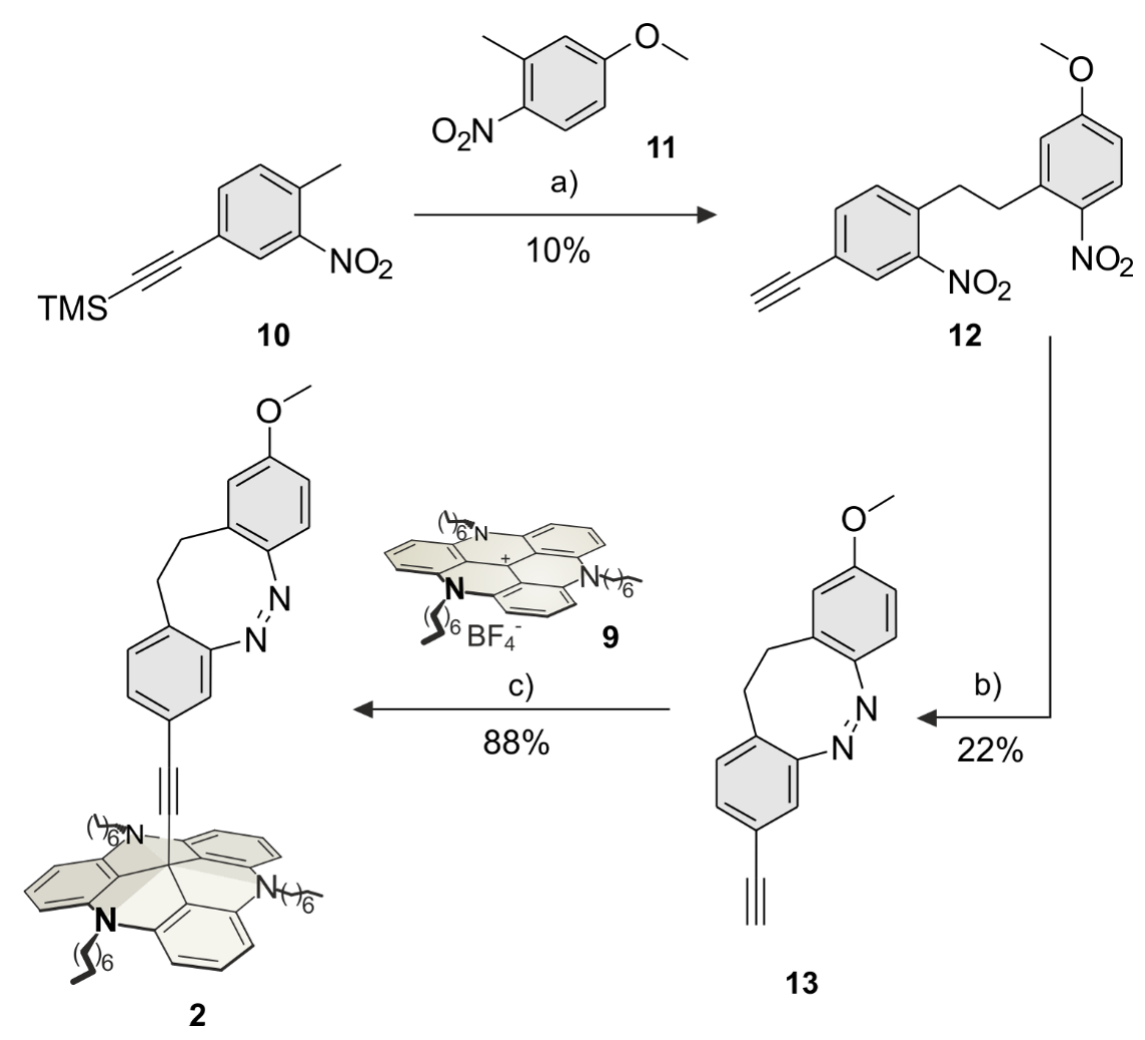

Scheme 2: Synthesis route of meta-diazocine platform 2. a) 1: $\left.\mathrm{KOt}-\mathrm{Bu}, \mathrm{THF}, 3 \min , 0^{\circ} \mathrm{C}, \mathrm{N}_{2} ; 2: \mathrm{Br}_{2}, 5 \min , 0^{\circ} \mathrm{C}, \mathrm{N}_{2} ; \mathrm{b}\right) 1: \mathrm{Ba}(\mathrm{OH})_{2}, \mathrm{Zn}, \mathrm{EtOH}, \mathrm{H}_{2} \mathrm{O}$, $4.75 \mathrm{~h}$, reflux; 2: $0.1 \mathrm{M} \mathrm{NaOH} / \mathrm{MeOH}, \mathrm{Cu}(\mathrm{II}) \mathrm{Cl}_{2}, 13 \mathrm{~h}$, rt; c) KOH, THF, $2 \mathrm{~h}$, reflux, $\mathrm{N}_{2}$.

The photophysical properties and the switching behavior of $\mathbf{1}$ and 2 were determined in solution (THF). The UV-vis spectra of $\mathbf{1}$ and $\mathbf{2}$ are shown before and after irradiation with $405 \mathrm{~nm}$ and $525 \mathrm{~nm}$. Both diazocine-TATAs $\mathbf{1}$ and $\mathbf{2}$ exhibit similar UV spectra. The $n \rightarrow \pi^{*}$ transition of $c i s-\mathbf{1}$ appears at $403 \mathrm{~nm}$ and at $494 \mathrm{~nm}$ in the trans-isomer. The corresponding absorption maxima in diazocine-TATA 2 are $409 \mathrm{~nm}$ (cis) and $493 \mathrm{~nm}$ (trans) (Figure 2).

The photostationary states of $\mathbf{1}$ and $\mathbf{2}$ were determined in toluene- $d_{8}$ by ${ }^{1} \mathrm{H}$ NMR measurements (Table 2). Optimal wavelengths for the cis $\rightarrow$ trans isomerization are $405 \mathrm{~nm}$ (1: 53\%
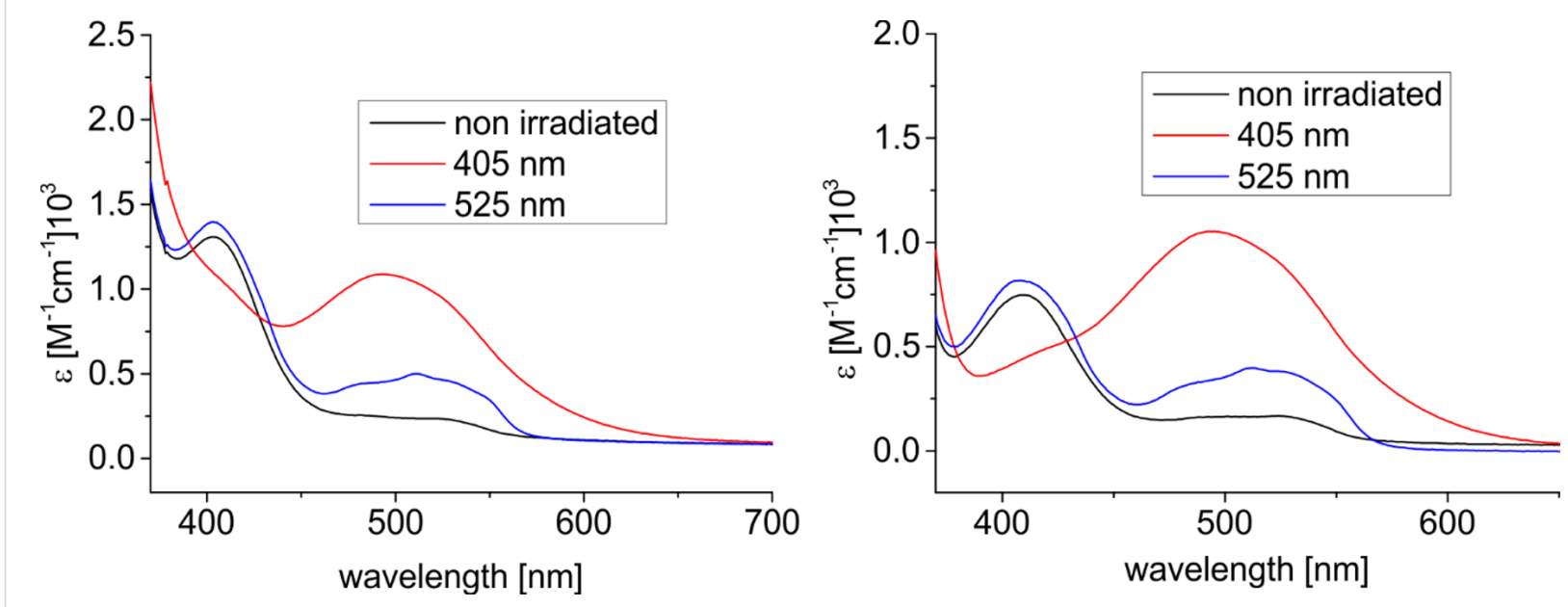

Figure 2: UV-vis spectra of 1 (left) and 2 (right) in THF at room temperature. Black: as synthesized, red: after irradiation with 405 nm, and blue: after irradiation with $525 \mathrm{~nm}$. 
trans, 2: $65 \%$ trans). Back-isomerization to the cis-isomer with $525 \mathrm{~nm}$ is nearly quantitative. The half-lives $(298 \mathrm{~K})$ are similar for both systems ( $2.12 \mathrm{~h}$ for $\mathbf{1}$ and $2.32 \mathrm{~h}$ for $\mathbf{2}$ ). The lack of conjugation between the azo function and the ethynyl spacer of 2 yields in a slightly higher half-life, which is in agreement with earlier results [11].

Table 2: Photostationary states (PSS) of para-diazocine-TATA 1 $(2.05 \mathrm{mmol} / \mathrm{L})$ and meta-diazocine-TATA 2 (2.27 mmol/L) upon irradiation with light of $405 \mathrm{~nm}, 525 \mathrm{~nm}$ and thermal isomerization half-life $\left(t_{1 / 2}\right)$ determined with ${ }^{1} \mathrm{H}$ NMR spectroscopy (in deuterated toluene) The activation energies $\left(E_{\mathrm{a}}\right)$ are calculated from the linear fit of an Arrhenius plot.

\begin{tabular}{lll} 
& para-diazocine 1 & meta-diazocine 2 \\
\hline PSS $(405 \mathrm{~nm})$ & $53 \%($ trans $)$ & $65 \%($ trans $)$ \\
PSS $(525 \mathrm{~nm})$ & $93 \%($ cis $)$ & $93 \%(c i s)$ \\
$t_{1 / 2}(290.5 \mathrm{~K})$ & $5.27 \mathrm{~h}$ & $5.76 \mathrm{~h}$ \\
$t_{1 / 2}(298 \mathrm{~K})$ & $2.12 \mathrm{~h}$ & $2.32 \mathrm{~h}$ \\
$t_{1 / 2}(308 \mathrm{~K})$ & $0.69 \mathrm{~h}$ & $0.73 \mathrm{~h}$ \\
$\mathrm{E}_{\mathrm{A}}\left(\mathrm{kJ} \mathrm{mol}^{-1}\right)$ & 86.5 & 84.7
\end{tabular}

\section{STM Measurements}

The adsorption behavior of the diazocine-TATA molecules on $\mathrm{Au}(111)$ surfaces was studied by STM at room temperature (Figure 3). Adlayers of both compounds show a hexagonally ordered superstructure with lattice constants of $\mathbf{1}$ and $\mathbf{2}$ being $(12.2 \pm 0.6) \AA$ and $(12.1 \pm 0.5) \AA$, respectively. Additionally, two rotational domains with an angle of $(15 \pm 4)^{\circ}$ are observed. Altogether these parameters are in good agreement with a $(\sqrt{ } 19 \times \sqrt{ } 19) R 23.4^{\circ}$ superstructure which has been also observed in previous STM investigations of TATA and azobenzene-TATA molecules with octyl ligands $[18,20,30]$.

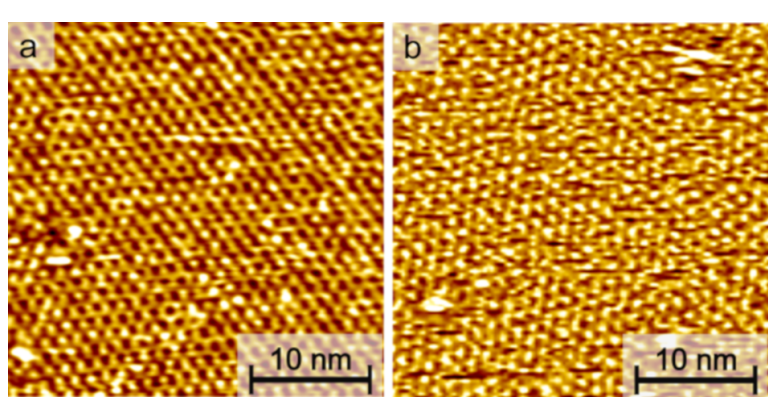

Figure 3: STM images $\left(30 \times 30 \mathrm{~nm}^{2}, U_{\text {bias }}=0.3 \mathrm{~V}, l_{\mathrm{t}}=40 \mathrm{pA}\right)$ of selfassembled monolayers of (a) compound $\mathbf{1}$ and (b) compound 2 on $\mathrm{Au}(111)$

\section{Conclusion}

In summary, we present the syntheses of two different diazocines mounted on TATA platforms $(\mathbf{1}, \mathbf{2})$. The photochem- ical switching between the stable cis and metastable transisomers was investigated. Upon irradiation with light of $405 \mathrm{~nm}$ diazocine-TATAs $\mathbf{1}$ and $\mathbf{2}$ convert to their trans-configurations in moderate to good yields. The metastable trans-isomers of $\mathbf{1}$ and 2 isomerize back to the cis-isomer with half-lives of $2.12 \mathrm{~h}$ and $2.32 \mathrm{~h}$ at $298 \mathrm{~K}$. The trans $\rightarrow$ cis activation energies with $86.5 \mathrm{~kJ} \mathrm{~mol}^{-1}$ for $\mathbf{1}$ and with $84.7 \mathrm{~kJ} \mathrm{~mol}^{-1}$ for $\mathbf{2}$ are similar to the structurally related azobenzenes [11]. Both diazocineTATAs form highly ordered monolayers on $\mathrm{Au}(111)$ surfaces. Further studies will include IRRAS measurements to determine the trans $\rightarrow$ cis isomerization kinetics on $\mathrm{Au}(111)$ surfaces.

\section{Experimental}

For detailed experimental procedures, including NMR, UV-vis and MS spectra see Supporting Information File 1, chapters I-IV, for kinetic studies see Supporting Information File 1, chapter $\mathrm{V}$.

\section{Supporting Information}

\section{Supporting Information File 1 \\ Analytical methods, experimental procedures, NMR and \\ UV spectra, kinetic studies and DFT calculations. \\ [https://www.beilstein-journals.org/bjoc/content/ supplementary/1860-5397-15-150-S1.pdf]}

\section{Acknowledgements}

The authors gratefully acknowledge financial support by the Deutsche Forschungsgesellschaft within the Sonderforschungsbereich 677, "Function by Switching".

\section{ORCID ${ }^{\circledR} \mathrm{iDs}$}

Roland Löw - https://orcid.org/0000-0002-3051-7831 Talina Rusch - https://orcid.org/0000-0001-8123-6792 Fynn Röhricht - https://orcid.org/0000-0001-9935-9256 Rainer Herges - https://orcid.org/0000-0002-6396-6991

\section{Preprint}

A non-peer-reviewed version of this article has been previously published as a preprint doi:10.3762/bxiv.2019.11.v1

\section{References}

1. Hauffe, K., Ed. Katalyse; DE GRUYTER: Berlin, New York, 1976; p 119. doi:10.1515/9783110829990

2. Ostbald, W. Z. Phys. Chem. 1894, 15, 705-706.

3. Oyama, S. T.; Somorjai, G. A. J. Chem. Educ. 1988, 65, 765-769. doi:10.1021/ed065p765

4. Shriver, D. F.; Atkins, P. W.; Langford, C. H. In Anorganische Chemie, 2nd ed.; Heck, J.; Kaim, W.; Weidenbruch, M., Eds.; Wiley-VCH: Weinheim, Germany, 1997; p 692.

5. Eyring, H. J. Chem. Phys. 1935, 3, 107-115. doi:10.1063/1.1749604 
6. Gowenlock, B. G. Q. Rev., Chem. Soc. 1960, 14, 133-145. doi:10.1039/qr9601400133

7. Hauser, A. Coord. Chem. Rev. 1991, 111, 275-290. doi:10.1016/0010-8545(91)84034-3

8. Xie, C.-L.; Hendrickson, D. N. J. Am. Chem. Soc. 1987, 109, 6981-6988. doi:10.1021/ja00257a013

9. Harvey, J. N. Phys. Chem. Chem. Phys. 2007, 9, 331-343. doi:10.1039/b614390c

10. Schreiner, P. R.; Reisenauer, H. P.; Pickard IV, F. C.; Simmonett, A. C.; Allen, W. D.; Mátyus, E.; Császár, A. G. Nature 2008, 453, 906-909. doi:10.1038/nature07010

11. Schlimm, A.; Löw, R.; Rusch, T.; Röhricht, F.; Strunskus, T.; Tellkamp, T.; Sönnichsen, F.; Manthe, U.; Magnussen, O.; Tuczek, F.; Herges, R. Angew. Chem., Int. Ed. 2019, 58, 6574-6578. doi:10.1002/anie.201814342

12. Hartley, G. S. J. Chem. Soc. 1938, 633-642. doi:10.1039/jr9380000633

13. Shinkai, S.; Kusano, Y.; Shigematsu, K.; Manabe, O. Chem. Lett. 1980, 9, 1303-1306. doi:10.1246/cl.1980.1303

14. Jung, U.; Schütt, C.; Filinova, O.; Kubitschke, J.; Herges, R.; Magnussen, O. J. Phys. Chem. C 2012, 116, 25943-25948. doi:10.1021/jp310451c

15. Jacob, H.; Ulrich, S.; Jung, U.; Lemke, S.; Rusch, T.; Schütt, C.; Petersen, F.; Strunskus, T.; Magnussen, O.; Herges, R.; Tuczek, F. Phys. Chem. Chem. Phys. 2014, 16, 22643-22650. doi:10.1039/c4cp03438d

16. Krekiehn, N. R.; Müller, M.; Jung, U.; Ulrich, S.; Herges, R.; Magnussen, O. M. Langmuir 2015, 31, 8362-8370. doi:10.1021/acs.langmuir.5b01645

17. Hagen, S.; Kate, P.; Peters, M. V.; Hecht, S.; Wolf, M.; Tegeder, P. Appl. Phys. A: Mater. Sci. Process. 2008, 93, 253-260. doi:10.1007/s00339-008-4831-5

18. Baisch, B.; Raffa, D.; Jung, U.; Magnussen, O. M.; Nicolas, C.; Lacour, J.; Kubitschke, J.; Herges, R. J. Am. Chem. Soc. 2009, 131, 442-443. doi:10.1021/ja807923f

19. Ulrich, S.; Jung, U.; Strunskus, T.; Schütt, C.; Bloedorn, A.; Lemke, S.; Ludwig, E.; Kipp, L.; Faupel, F.; Magnussen, O.; Herges, R.

Phys. Chem. Chem. Phys. 2015, 17, 17053-17062. doi:10.1039/c5cp01447f

20. Kuhn, S.; Baisch, B.; Jung, U.; Johannsen, T.; Kubitschke, J.; Herges, R.; Magnussen, O. Phys. Chem. Chem. Phys. 2010, 12, 4481. doi:10.1039/b922882a

21. Duval, H. Bull. Soc. Chim. Fr. 1910, 7, 727.

22. Siewertsen, R.; Neumann, H.; Buchheim-Stehn, B.; Herges, R.; Näther, C.; Renth, F.; Temps, F. J. Am. Chem. Soc. 2009, 131, 15594-15595. doi:10.1021/ja906547d

23. Hartley, G. S. Nature 1937, 140, 281. doi:10.1038/140281a0

24. Yaliraki, S. N.; Ratner, M. A. Ann. N. Y. Acad. Sci. 2002, 960, 153-162. doi:10.1111/j.1749-6632.2002.tb03030.x

25. Mayor, M.; Büschel, M.; Fromm, K. M.; Lehn, J.-M.; Daub, J. Ann. N. Y. Acad. Sci. 2002, 960, 16-28. doi:10.1111/j.1749-6632.2002.tb03022.x

26. Wahhab, A.; Therrien, E. Small Molecule Inhibitors of Protein Arginine methyltransferases. PCT Pat. Appl. WO2008104077 A1, Feb 28, 2007.

27. Moormann, W.; Langbehn, D.; Herges, R. Synthesis 2017, 49, 3471-3475. doi:10.1055/s-0036-1590685

28. Laursen, B. W.; Krebs, F. C. Chem. - Eur. J. 2001, 7, 1773-1783. doi:10.1002/1521-3765(20010417)7:8<1773::aid-chem17730>3.0.co;2f
29. Park, K.; Lee, B. M. Novel phenylethynyl benzamide glucokinase activator and method for preparing same. PCT Pat. Appl. WO2014112798 A1, Jan 16, 2013.

30. Lemke, S.; Ulrich, S.; Claußen, F.; Bloedorn, A.; Jung, U.; Herges, R.; Magnussen, O. M. Surf. Sci. 2015, 632, 71-76. doi:10.1016/j.susc.2014.08.028

\section{License and Terms}

This is an Open Access article under the terms of the Creative Commons Attribution License

(http://creativecommons.org/licenses/by/4.0). Please note that the reuse, redistribution and reproduction in particular requires that the authors and source are credited.

The license is subject to the Beilstein Journal of Organic Chemistry terms and conditions:

(https://www.beilstein-journals.org/bjoc)

The definitive version of this article is the electronic one which can be found at: doi:10.3762/bjoc. 15.150 